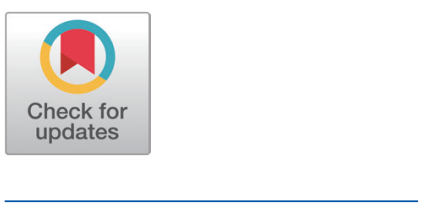

Received: Feb 10, 2021

Revised: Feb 24, 2021

Accepted: Feb 28, 2021

*Corresponding author Minseok Kim

Department of Animal Science, College of Agriculture and Life Sciences,

Chonnam National University, Gwangju 61186 , Korea.

Tel: +82-62-530-2128

E-mail: mkim2276@jnu.ac.kr

Copyright $@ 2021$ Korean Society of Animal Sciences and Technology.

This is an Open Access article distributed under the terms of the Creative Commons Attribution

Non-Commercial License (http:// creativecommons.org/licenses/by$\mathrm{nc} / 4.0 /$ ) which permits unrestricted non-commercial use, distribution, and reproduction in any medium, provided the original work is properly cited.

ORCID

Se-Woon Hong

https://orcid.org/0000-0002-9647-5523

Jinseon Park

https://orcid.org/0000-0002-6281-4910

Hanna Jeong

https://orcid.org/0000-0002-4419-3137

Minseok Kim

https://orcid.org/0000-0002-8802-5661

Competing interests

No potential conflict of interest relevant

to this article was reported.

Funding sources

This work was carried out with the

\section{Evaluation of the microbiome composition in particulate matter inside and outside of pig houses}

\author{
Se-Woon Hong ${ }^{1,2,3}$, Jinseon Park ${ }^{3}$, Hanna Jeong ${ }^{1,2}$ and Minseok Kim ${ }^{3,4 *}$ \\ ${ }^{1}$ Department of Rural and Biosystems Engineering, Chonnam National University, Gwangju 61186, \\ Korea \\ ${ }^{2}$ Education and Research Unit for Climate-Smart Reclaimed-Tideland Agriculture, Chonnam National \\ University, Gwangju 61186, Korea \\ ${ }^{3}$ AgriBio Institute of Climate Change Management, Chonnam National University, Gwangju 61186, \\ Korea \\ ${ }^{4}$ Department of Animal Science, College of Agriculture and Life Sciences, Chonnam National University, \\ Gwangju 61186, Korea
}

\section{Abstract}

Particulate matter (PM) produced in pig houses may contain microbes which can spread by airborne transmission, and PM and microbes in PM adversely affect human and animal health. To investigate the microbiome in PM from pig houses, nine PM samples were collected in summer 2020 inside and outside of pig houses located in Jangseong-gun, Jeollanam-do Province, Korea, comprising three PM samples from within a nursery pig house (I-NPH), three samples from within a finishing pig house (I-FPH), and three samples from outside of the pig houses (O-PH). Microbiomes were analyzed using 16S rRNA gene amplicon sequencing. Firmicutes was the most dominant phylum and accounted for $64.8 \%-97.5 \%$ of total sequences in all the samples, followed by Proteobacteria $(1.4 \%-21.8 \%)$ and Bacteroidetes $(0.3 \%-13.7 \%)$. In total, 31 genera were represented by $>0.3 \%$ of all sequences, and only Lactobacillus, Turicibacter, and Aerococcus differed significantly among the three PM sample types. All three genera were more abundant in the I-FPH samples than in the $\mathrm{O}-\mathrm{PH}$ samples. Alpha diversity indices did not differ significantly among the three PM types, and a principal coordinate analysis suggested that overall microbial communities were similar across PM types. The concentration of PM did not significantly differ among the three PM types, and no significant correlation of PM concentration with the abundance of any potential pathogen was observed. The present study demonstrates that microbial composition in PM inside and outside of pig houses is similar, indicating that most microbe-containing PM inside pig houses leaks to the outside from where it, along with microbe-containing PM on the outside, may re-enter the pig houses. Our results may provide useful insights regarding strategies to mitigate potential risk associated with pig farming PM and pathogens in PM.

Keywords: 16S rRNA gene amplicon sequencing, Microbiome, Particulate matter, Pathogen, Pig house 
support of "Cooperative Research Program for Agriculture Science and Technology Development (Project No. PJ01424801)" Rural Development Administration, Korea.

Acknowledgements

Not applicable.

Availability of data and material Upon reasonable request, the datasets of this study can be available from the corresponding author.

\section{Authors' contributions}

Conceptualization: Hong SW, Kim M.

Data curation: Park J, Jeong $\mathrm{H}$.

Formal analysis: Park $\mathrm{J}$, Jeong $\mathrm{H}$.

Methodology: Hong SW, Park J, Jeong $\mathrm{H}$ Kim M.

Validation: Hong SW, Kim M.

Writing - original draft: Hong SW, Kim M. Writing - review \& editing: Kim M.

Ethics approval and consent to participate This article does not require IRB/IACUC approval because there are no human and animal participants.

\section{INTRODUCTION}

Enclosed housing with mechanical ventilation systems has recently become increasingly common in pig farming [1]. From such buildings housing animals at high densities, particulate matter (PM), which is a major air pollutant, is emitted and adversely affects human and animal respiratory health [2,3]. PM from pig houses comprises feces, feedstuff, hair, bedding particles, and animal skin, where feces and feeds occur as smaller particles than biological structures such as animal skin and hair [4], and feedstuff accounts for a considerable proportion in PM [5]. Airborne PM can lead to increased prevalence of respiratory diseases such as asthma [6] and chronic obstructive pulmonary disease [7] in humans. Moreover, airborne PM negatively affects respiratory health of pigs [8], and nursery pigs are more susceptible to respiratory disease than finishing pigs [9]. Tang et al. [10] suggested that swine respiratory diseases occur because of oxidative stress and inflammatory responses induced by PM.

Microbes contained in PM leaking from pig houses can spread by airborne transmission; however, culture-based methods used to investigate airborne microbes such as Escherichia coli in pig houses [9] do not suffice to resolve taxonomic diversity of such microbiomes owing to limitation of culture media [11]. Culture-independent methods such as next-generation sequencing can help identify various microbiota [11], and this approach was previously used to resolve the composition of airborne microbes in PM emitted from pig houses [12-15]. The most dominant bacterial phylum in pig houses is Firmicutes [12,13,15]; however, Aerococcus viridans, Bacillus cereus, Serratia marcescens, Vagococcus fluvialis, Clostridium spp., Enterococcus spp., Staphylococcus spp., and Streptococcus spp., which are potential airborne pathogens, have also been traced [16].

The community structure of airborne microbes in PM of pig houses may depend on factors such as environment, source, season, and air pollution levels [17]. Swine feces are the main component of PM [4], and they contain various microbes that are affected by diet, host genetics and age, and environment [18]. Therefore, identification of the microbiome composition in PM is of particular interest for improving pig productivity and health of pig farmers in South Korea. The objective of our study was to investigate microbiomes in PM emitted from pig houses in South Korea and to compare the differences in PM microbiomes between samples collected inside and outside of pig houses.

\section{MATERIALS AND METHODS}

\section{Collection of PM samples}

Samples were collected in a pig farm housing approximately 9,000 pigs and located in Jangseonggun, Jeollanam-do Province, Korea. In summer 2020, PM samples were collected at exhaust fans of a 1,000-head pig finishing building and an enclosed 390-head pig nursery section selected from eight enclosed sections in a nursery building (Fig. 1A). Outdoor PM concentrations were measured in an open space on a hill where the buildings' ventilation systems were assumed to not directly affect air PM concentrations (Fig. 1B).

Three $\mathrm{PM}$ indices, $\mathrm{PM}_{2.5}(\mathrm{PM}<2.5 \mu \mathrm{m}$ diameter $), \mathrm{PM}_{10}(\mathrm{PM}<10 \mu \mathrm{m}$ diameter $)$, and total suspended particles (TSP; PM smaller than approximately 50-100 $\mu \mathrm{m}$ diameter), were recorded simultaneously and gravimetrically using a cassette and two impactor samplers (PEM, SKC, Blandford Forum, UK) connected to portable air pumps (AirCheck, SKC). The air pumps provided a flow rate of $2 \mathrm{~L} / \mathrm{min}$ for TSP and $4 \mathrm{~L} / \mathrm{min}$ for $\mathrm{PM}_{2.5}$ and $\mathrm{PM}_{10}$.

Filters were weighed in a dehumidified chamber ( $30 \pm 5 \%$ relative humidity) before and after sampling using a precise balance (BM-22, A\&D, Tokyo, Japan). All filters were stabilized for 24 
A

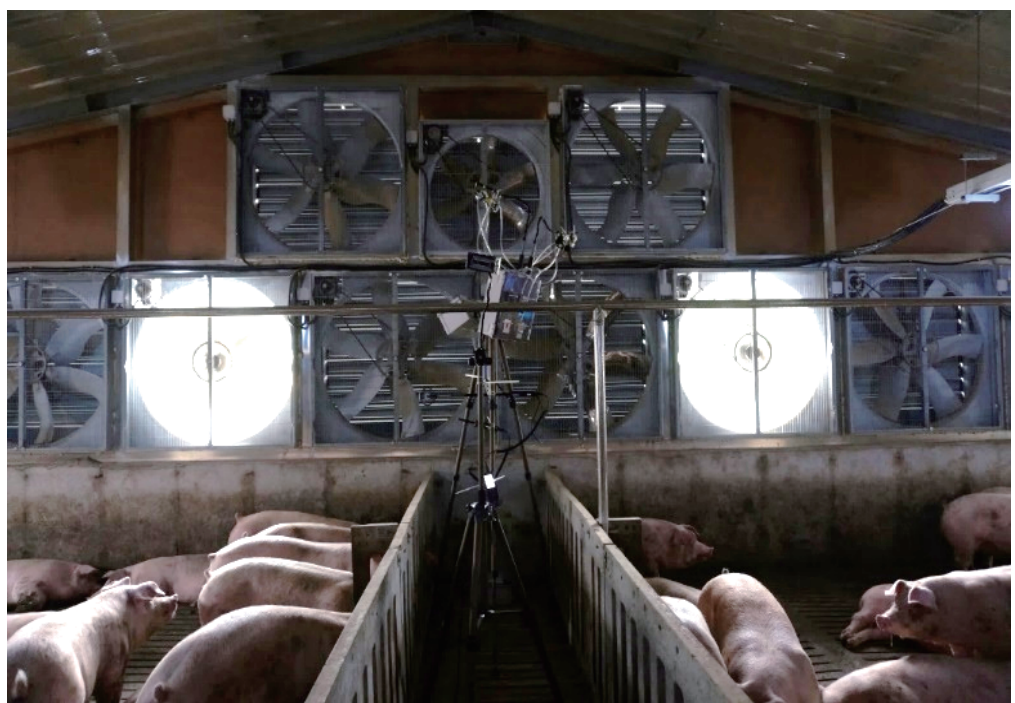

B

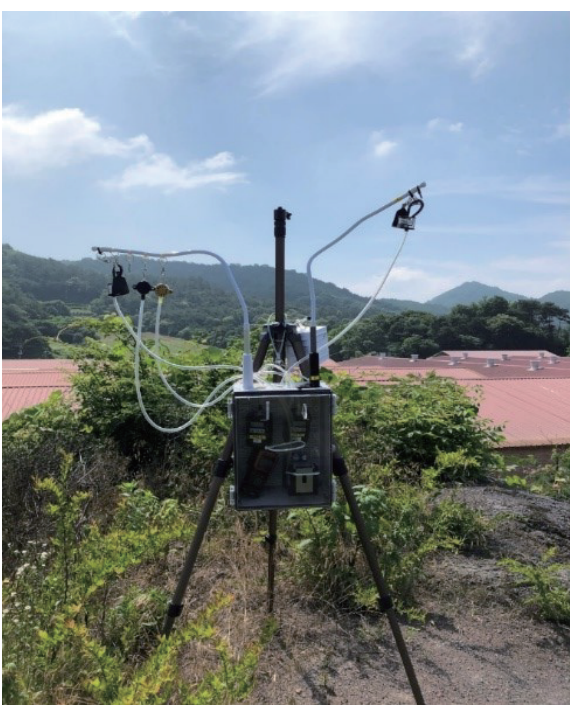

Fig. 1. Measurement of particulate matter (PM) inside and outside the pig house. (A) PM sampling inside the pig house. (B) PM sampling outside the pig house.

hours in the chamber and were then weighed three times. The weight increment after sampling was considered to represent the amount of PM, and PM concentration was calculated as the mass of collected PM divided by the air volume that had passed through the filter.

A set of instruments for measuring the three PM indices was installed within protective housing in front of exhaust fans and at the outdoor sampling site. Measurement of the three PM indices was carried out for 6 h (from 10.00 a.m. to 16.00 p.m.) on three different days in summer 2020. The exhaust fans were located on the side walls of the nursery building, whereas the exhaust fans of the pig finishing building were placed on the end wall in summer.

\section{DNA extraction and sequencing}

Using sterilized scissors, the filters capturing $\mathrm{PM}_{2.5}, \mathrm{PM}_{10}$, and TSP were cut in small pieces, which were then pooled based on the following three types: 1) three pooled PM samples collected on three different days $(\mathrm{n}=3)$ from inside the nursery pig house (I-NPH), 2) three pooled PM samples collected on three different days $(n=3)$ from inside the finishing pig house (I-FPH), and 3) three pooled PM samples collected on three different days $(n=3)$ from outside of the pig houses (O-PH). After the filter pieces were transferred to bead tubes, metagenomic DNA was extracted using the bead-beating plus column $(\mathrm{RBB}+\mathrm{C})$ method [19].

Bacterial 16S rRNA gene amplicons including the V3-V4 hypervariable region were produced using primers 341F (5'-CCTACGGGNGGCWGCAG-3') and 805R (5'-GAC TACHVGGGTATCTAATCC-3') and were then subjected to high-throughput sequencing on an Illumina MiSeq platform (Illumina, San Diego, CA, USA) as described previously [20]. The resulting sequences were assembled using FLASH software [21], and microbiome analysis was conducted using the QIIME 1.9.1 software package [22] as described previously [23,24].

\section{Statistical analyses}

The proportion of total reads per taxon was log-transformed to produce a normal distribution. Log-transformed proportion values and DNA concentrations were compared among the three PM sample types (I-NPH, I-FPH, and O-PH) using an analysis of variance followed by Duncan's 
multiple range test using XLSTAT statistical software version 2019.4.2 (Addinsoft, New York, NY, USA). Statistical significance is reported at $p<0.05$. Spearman's rank correlation was conducted to analyze correlations among PM concentrations, DNA concentrations, and major taxa using XLSTAT statistical software.

\section{RESULTS}

\section{Microbiome composition}

In total, 351,016 sequences were produced from the nine PM samples. Phyla or genera with an abundance of $>0.2 \%$ of all sequences, on average, were considered "major taxa" and were subjected to statistical analysis. Firmicutes was the dominant phylum accounting for $64.8 \%-97.5 \%$ of the sequences in individual samples, followed by Proteobacteria (1.4\%-21.8\%) and Bacteroidetes $(0.3 \%-13.7 \%)$ (Fig. 2). The proportions of these three major phyla did not differ significantly $(p\rangle$ 0.05 ) among the three PM types. The remaining minor phyla accounted for $<0.1 \%$ of all sequences, on average, and included Spirochaetes, Deinococcus-Thermus, Candidatus Melainabacteria, Chloroflexi, Fusobacteria, Verrucomicrobia, Tenericutes, Acidobacteria, Gemmatimonadetes, Chlamydiae, Elusimicrobia, Fibrobacteres, and Planctomycetes.

At genus level, Clostridium was predominant and accounted for $28.1 \%$ of sequences, on average, across the nine PM samples. The second dominant genus was Bacillus at 25.2\%, on average, followed by Terrisporobacter (9.0\%), Turicibacter (5.4\%), Lactobacillus (2.6\%), Prevotella (2.5\%), Staphylococcus (2.2\%), Curvibacter (2.2\%), Weissella (1.6\%), Sediminibacterium (1.2\%), Roseburia (1.1\%), and Blautia (1.0\%). Genera accounting for < $1.0 \%$ of all sequences, on average, included Eubacterium (0.9\%), Bradyrbizobium (0.8\%), Pediococcus (0.7\%), Faecalibacterium (0.6\%), Mediterraneibacter (0.5\%), Streptococcus (0.5\%), Gemmiger (0.5\%), Ruminococcus (0.4\%), Hungateiclostridium (0.4\%), Corynebacterium (0.4\%), Sphingomonas (0.4\%), Aerococcus (0.4\%), Oscillibacter (0.4\%), Barnesiella (0.4\%), Pelomonas (0.3\%), Flintibacter (0.3\%), Phascolarctobacterium (0.3\%), Holdemanella (0.3\%), and Dorea $(0.3 \%)$. Among the major genera, the proportion of Lactobacillus was significantly larger $(p<0.05)$ in the I-NPH and I-FPH samples than in the O-PH samples (Fig. 3A). The proportion of Turicibacter was significantly larger in the I-FPH samples than in the other two PM types, while that of Aerococcus was significantly larger $(p<0.05)$ in the I-NPH and I-FPH samples than in the $\mathrm{O}-\mathrm{PH}$ samples (Figs. 3B and C).

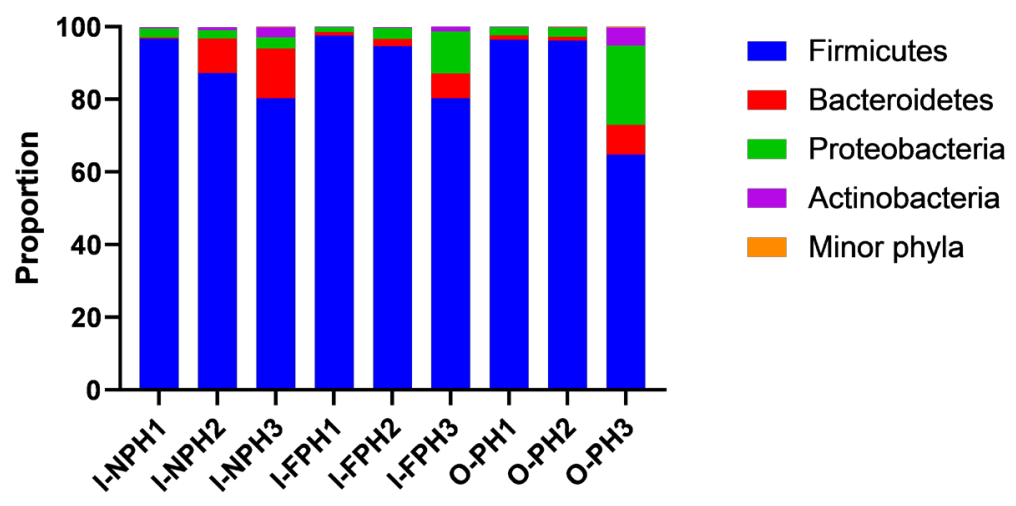

Fig. 2. Microbiome profiles in particulate matter collected inside and outside of a pig house. I-NPH, inside the nursery pig house; I-FPH, inside the finishing pig house; O-PH, outside of the pig house. 
A
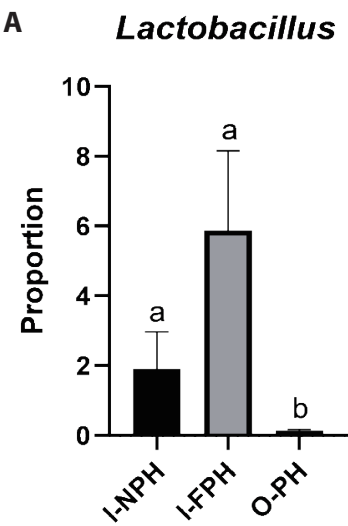

B

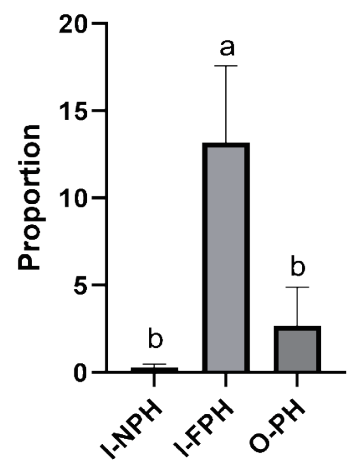

C

Aerococcus

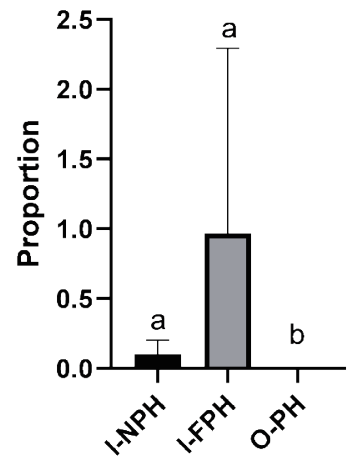

Fig. 3. Microbiome profiles in particulate matter collected inside and outside of the pig house. ${ }^{a, b}$ Different superscript letters indicate significant differences. I-NPH, inside the nursery pig house; I-FPH, inside the finishing pig house; O-PH, outside of the pig house.

\section{Alpha and beta diversity}

Alpha diversity analysis showed that the observed operational taxonomic unit (OTU), Chao1, Shannon, and Inverse Simpson indices did not differ significantly $(p>0.05)$ among the three PM types (Table 1). A beta diversity principal coordinate analysis ( $\mathrm{PCoA})$ based on weighted and unweighted UniFrac distances revealed that individual microbiomes of the nine PM samples were not distinct, indicating that the compositions of PM microbiomes were similar (Fig. 4).

Table 1. Alpha diversity indices of the three particulate matter groups

\begin{tabular}{lcccc}
\hline Particulate matter group ${ }^{1)}$ & Observed OTUs & Chao1 & Shannon & Inverse Simpson \\
\hline I-NPH $(n=3)$ & $245.33^{\mathrm{a}}$ & $253.28^{\mathrm{a}}$ & $4.00^{\mathrm{a}}$ & $0.75^{\mathrm{a}}$ \\
I-FPH $(\mathrm{n}=3)$ & $268.00^{\mathrm{a}}$ & $300.54^{\mathrm{a}}$ & $3.49^{\mathrm{a}}$ & $0.76^{\mathrm{a}}$ \\
O-PH $(\mathrm{n}=3)$ & $224.67^{\mathrm{a}}$ & $233.33^{\mathrm{a}}$ & $2.94^{\mathrm{a}}$ & $0.62^{\mathrm{a}}$ \\
\hline
\end{tabular}

${ }^{1)}$ Means were compared among the three PM groups using an ANOVA followed by Duncan's multiple range test. ${ }^{a}$ Means with the same superscript letter represent non-significant differences $(p>0.05)$.

OTU, operational taxonomic unit; I-NPH, inside the nursery pig house; I-FPH, inside the finishing pig house; O-PH, outside of the pig house.

A

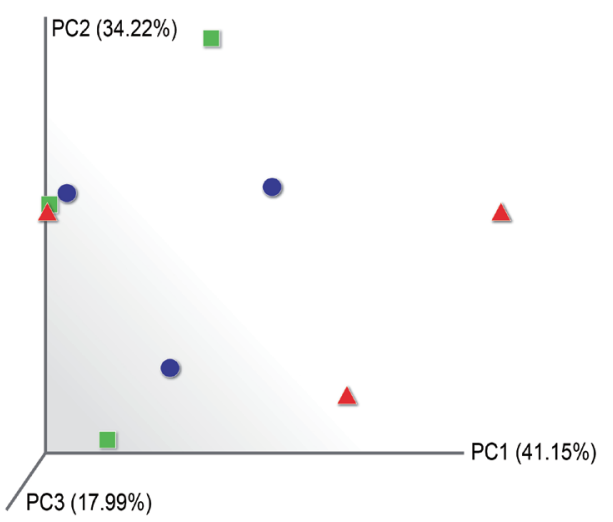

B

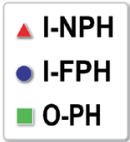

Fig. 4. Weighted $(A)$ and unweighted $(B)$ principal coordinate analysis indicating similarity among the three groups of particulate matter (PM) samples. Microbiomes of the three sampling groups were not separated. NPH, inside the nursery pig house; I-FPH, inside the finishing pig house; O-PH, outside of the pig house. 


\section{Correlation analysis}

PM and metagenomic DNA concentrations did not differ significantly $(p>0.05)$ among the three PM types (Table 2). PM concentration did not show a significant correlation with DNA concentrations; however, it was significantly negatively correlated with the proportions of Curvibacter, Sediminibacterium, Bradyrbizobium, and Pelomonas (Fig. 5). The remaining major genera including pathogens did not show a significant correlation with PM concentration.

\section{DISCUSSION}

Pig farming at high animal densities can lead to considerable emission of PM originating from feces, feedstuff, skin, and hair [15]. Potential pathogens in such PM can cause health problems among farmers and neighboring residents [25]. Swine breeds and diets vary among farms in different countries, and factors such as diet, host genetics and age, and environment can affect microbiomes in pig feces [18]. To the best of our knowledge, the current study is the first to assess the composition of microbiomes in PM inside and outside of pig houses in the Korea, and it may provide useful information to reduce potential risks associated with PM leaking from pig houses.

Previous studies reported that Firmicutes is the predominant phylum in PM from pig house,

Table 2. Particulate matter and DNA concentrations in samples collected inside and outside of pig houses $^{1)}$

\begin{tabular}{cccc}
\hline \multicolumn{1}{c}{ Variable } & I-NPH $(\mathbf{n}=\mathbf{3})$ & I-FPH $(\mathbf{n}=3)$ & O-PH $(\mathbf{n}=\mathbf{3})$ \\
\hline Particulate matter $\left(\mu \mathrm{g} / \mathrm{m}^{3}\right)^{2)}$ & $892.6 \pm 200.1^{\mathrm{a}}$ & $1,282.2 \pm 509.9^{\mathrm{a}}$ & $601.4 \pm 239.8^{\mathrm{a}}$ \\
Metagenomic DNA $\left(\mathrm{ng} / \mathrm{m}^{3}\right)^{3)}$ & $531.3 \pm 209.0^{\mathrm{a}}$ & $481.3 \pm 242.5^{\mathrm{a}}$ & $280.3 \pm 140.0^{\mathrm{a}}$ \\
\hline
\end{tabular}

1) Shown are the means \pm standard error of the mean $(n=3)$.

${ }^{2}$ Particulate matter contained $\mathrm{PM}_{2.5}, \mathrm{PM}_{10}$, and TSP.

${ }^{3}$ Total community DNA was extracted from particulate matter.

${ }^{a}$ Means with the same superscript letter represent non-significant differences.

I-NPH, inside the nursery pig house; I-FPH, inside the finishing pig house; O-PH, outside of the pig house; TSP, total suspended particles.

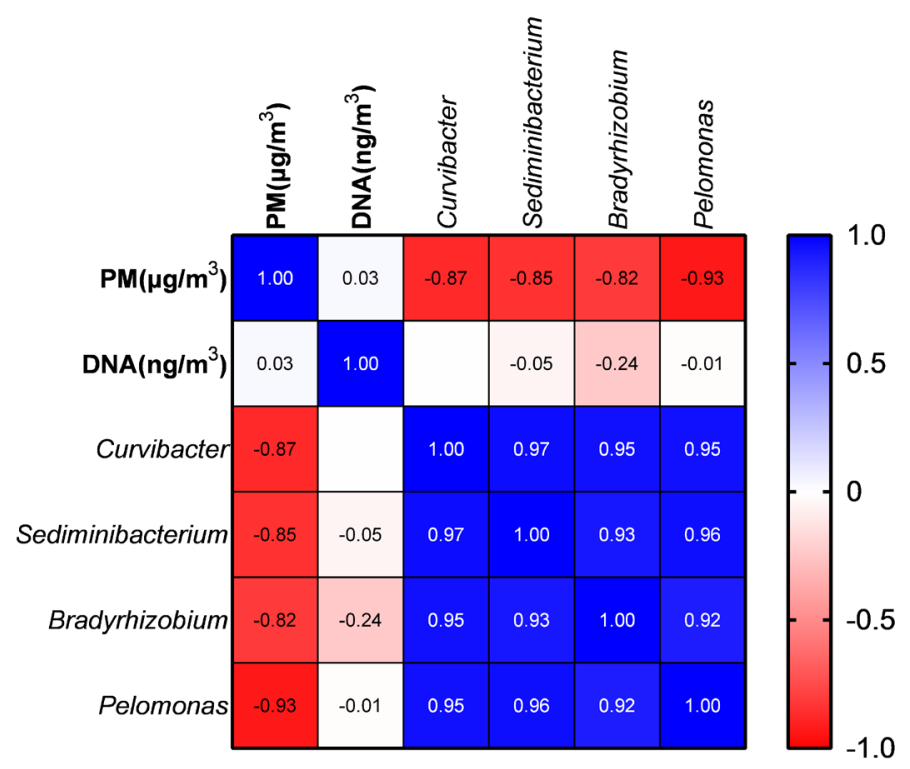

Fig. 5. Correlations between particulate matter (PM) and genera (or metagenomic DNA). Among the major genera, only four genera showed a significant correlation with PM. 
regardless of season $[2,15,26]$, and our results are in line with these findings. As Firmicutes is the most abundant phylum in the pig gut microbiome during all growth stages [18], its high abundance in PM is likely due to bacteria originating from feces. Moreover, other major genera identified in the present study seemed to originate from feces. Clostridium was the predominant genus in PM, which may have various functions: Wang et al. [18] proposed that butyrate-producing Clostridium butyricum contributes to gut health, and its abundance is positively correlated with body weight. Clostridium herbivorans can degrade cellulose in enrichment cultures with swine feces [27], while some Clostridium spp. can ferment amino acids and produce ammonia [28]. As Clostridium spp. produce odorous products such as volatile fatty acids and ammonia, Clostridium has been considered one of major contributors to odor from swine farms [28]. Terrisporobacter was also identified as one of the dominant genera in the gut of pigs [29]. Bacillus spp. are typically used as feed additives and are abundant in pig feces [30], which may explain why it was the second most abundant genus in PM in the present study. Turicibacter contributes to increasing body weight and improving immune functions in pigs [18], while Lactobacillus spp. are commonly used as probiotics [31] which can degrade mycotoxins derived from contaminated feedstuff [32]. Lactic acid-producing Weissella has also been found in pig feces [33]. Prevotella, Roseburia, and Blautia produce short-chain fatty acids as fermentation products in the intestine of pigs [34]. Thus, most of the dominant microbes in PM from pig farms seem to originate predominantly from feces because of larger bacterial biomass in feces than in feedstuff, skin, and hair. Maintenance of pig gut health is thus important to reduce the prevalence of pathogens in PM emitted from pig farms.

Some genera in PM from pig houses were pathogens. Although most Clostridium spp. contribute to gut health and help increase body weight of pigs, some Clostridium spp. are potential pathogens [35]. Staphylococcus is the predominant genus on the skin of Korean people [36], and it is also common in pig houses and is part of the pig skin microbiome [37,38]. However, Staphylococcus byicus is associated with pig skin disease [37], and Staphylococcus aureus may cause skin or respiratory infections in humans and can be transmitted from pigs to humans via bioaerosols [39]. Although the assumed main function of Streptococcus spp. in the pig gut is to promote animal growth [18], Streptococcus suis is an important zoonotic pathogen in pigs and is ubiquitous in most countries [40]. The genus Escherichia including the pathogenic Escherichia coli occurred at only $0.01 \%$ of all sequences in the present study. In addition, biosafety is important to prevent spreading of potential pathogens originating from sources other than swine feces.

Among the major genera, Clostridium and Bacillus spp. are typically predominant, not only in pig manure [41,42] but also in soil [43-45]. Therefore, pig manure and soil sources outside pig houses may contribute to the high abundance of Clostridium and Bacillus spp. in PM outside a pig house, whereas pig feces are presumably the source of bacteria of these two genera that occur at high abundances in PM inside the pig house. It seems that microbe-containing PM originating from inside the pig house leaks to the outside and then mixes with microbe-containing PM originating from outside the pig house. The mixed microbe-containing PM is thus presumed to have re-entered the buildings.

Lactobacillus, which plays an important role in maintaining gut health, was more abundant inside the pig house than outside. This is probably because Lactobacillus is predominant in feces of piglets and finishing pigs but not in sources outside the pig houses such as pig manure and soil. The abundance of Turicibacter increases with increasing body weight; thus, this genus is more abundant in finishing pig houses than in piglet houses [18]. Aerococcus spp. are pathogenic and have been isolated from clinical specimens of pigs [46,47]. In the present study, highly abundant Aerococcus inside the pig house seemed to be a result of infections in pigs. A previous study also reported that Aerococcus is highly abundant in PM from pig houses [16]. Farm workers may potentially 
be exposed to this pathogen contained in PM inside of pig houses. Therefore, reducing potential pathogens in pigs may help mitigate health problems in farmers and neighboring residents.

Alpha diversity indices and the beta diversity PCoA demonstrated that microbiomes were similar inside and outside of the pig houses. It seemed that most microbe-containing PM from inside pig houses leaked to the outside and then re-entered the buildings. Therefore, an increase in potential pathogen abundance and PM containing feces may cause health problems in farmers and neighboring residents. Maintaining pig gut health may help reduce the prevalence of fecal pathogens and mitigate potential risks associated with PM from pig houses. As described above, microbes from pig manure outside pig houses may mix with PM and then re-enter the buildings, which may also explain the similarity of the respective microbiomes.

PM concentrations were not correlated with the abundance of major genera, including pathogens in the pig gut. A previous study suggested a positive correlation between pathogen abundance and PM concentration [48], which was not confirmed by the results of the current study. The abundance of pathogens seems to be influenced by pig gut health rather than by the amount of feces; thus, maintaining gut health may be an important factor to help reduce the abundance of pathogens in PM. Abundances of Curvibacter, Sediminibacterium, Bradyrbizobium, and Pelomonas were negatively correlated with PM concentrations; however, these genera typically originate from soil or water [49-52], and even though PM concentrations increase, abundances of microbes originating from soil and water in PM may remain similar, whereas abundances of microbes from pig feces may be variable depending on pig gut health.

\section{CONCLUSION}

Our results suggest that pig feces are the main source of the PM from pig houses and of most of the dominant microbes in PM. Pathogen abundance was not correlated with PM concentrations, and pig gut health seems to affect the prevalence of pathogens. The overall composition of PM microbiomes was similar inside and outside of pig houses. However, among the two predominant genera Clostridium and Bacillus, some species seemed to originate from feces deposited inside the pig houses, whereas other species seemed to originate from pig manure and soil sources outside the pig house. It seems that microbes in PM inside pig houses leak to the outside and then mix with microbes in PM outside, after which they re-enter the buildings. Maintenance of pig gut health, as well as biosafety inside and outside of pig houses, may help reduce potential risks associated with pathogens in PM inside and outside of pig houses.

\section{REFERENCES}

1. Kim KY, Ko HJ. Indoor distribution characteristics of airborne bacteria in pig buildings as influenced by season and housing type. Asian-Australas J Anim Sci. 2019;32:742-7. https://doi. org/10.5713/ajas.18.0415

2. Hong PY, Li XZ, Yang XF, Shinkai T, Zhang YH, Wang XL, et al. Monitoring airborne biotic contaminants in the indoor environment of pig and poultry confinement buildings. Environ Microbiol. 2012;14:1420-31. https://doi.org/10.1111/j.1462-2920.2012.02726.x

3. Kalkowska DA, Boender GJ, Smit LAM, Baliatsas C, Yzermans J, Heederik DJJ, et al. Associations between pneumonia and residential distance to livestock farms over a five-year period in a large population-based study. PLOS ONE. 2018;13:e0200813. https://doi.org/10.1371/ journal.pone.0200813

4. Cambra-López M, Torres AG, Aarnink AJA, Ogink NWM. Source analysis of fine and 
coarse particulate matter from livestock houses. Atmos Environ. 2011;45:694-707. https://doi. org/10.1016/j.atmosenv.2010.10.018

5. Shen D, Wu S, Li ZJ, Tang Q, Dai PY, Li YS, et al. Distribution and physicochemical properties of particulate matter in swine confinement barns. Environ Pollut. 2019;250:746-53. https:// doi.org/10.1016/j.envpol.2019.04.086

6. de Groot LES, Liu DY, Dierdorp BS, Fens N, van de Pol MA, Sterk PJ, et al. Ex vivo innate responses to particulate matter from livestock farms in asthma patients and healthy individuals. Environ Health. 2020;19:78. https://doi.org/10.1186/s12940-020-00632-8

7. Palmberg L, Sundblad BM, Ji J, Karén J, Larsson K. Cholinergic mechanisms in an organic dust model simulating an acute exacerbation in patients with COPD. Int J Chron Obstruct Pulmon Dis. 2018;13:3611-24. https://doi.org/10.2147/COPD.S171495

8. Michiels A, Piepers S, Ulens T, Van Ransbeeck N, Del Pozo Sacristán R, Sierens A, et al. Impact of particulate matter and ammonia on average daily weight gain, mortality and lung lesions in pigs. Prev Vet Med. 2015;121:99-107. https://doi.org/10.1016/j.prevetmed.2015.06.011

9. Yao HQ Choi HL, Lee JH, Suresh A, Zhu K. Effect of microclimate on particulate matter, airborne bacteria, and odorous compounds in swine nursery houses. J Anim Sci. 2010;88:370714. https://doi.org/10.2527/jas.2009-2399

10. Tang Q, Huang K, Liu JZ, Wu S, Shen D, Dai PY, et al. Fine particulate matter from pig house induced immune response by activating TLR4/MAPK/NF- $\kappa$ B pathway and NLRP3 inflammasome in alveolar macrophages. Chemosphere. 2019;236:124373. https://doi. org/10.1016/j.chemosphere.2019.124373

11. Kim M, Park T, Yu Z. Metagenomic investigation of gastrointestinal microbiome in cattle. Asian-Australas J Anim Sci. 2017;30:1515-28. https://doi.org/10.5713/ajas.17.0544

12. Boissy RJ, Romberger DJ, Roughead WA, Weissenburger-Moser L, Poole JA, LeVan TD. Shotgun pyrosequencing metagenomic analyses of dusts from swine confinement and grain facilities. PLOS ONE. 2014;9:e95578. https://doi.org/10.1371/journal.pone.0095578

13. Kristiansen A, Saunders AM, Hansen AA, Nielsen PH, Nielsen JL. Community structure of bacteria and fungi in aerosols of a pig confinement building. FEMS Microbiol Ecol. 2012;80:390-401. https://doi.org/10.1111/j.1574-6941.2012.01305.x

14. Liu DY, Mariman R, Gerlofs-Nijland ME, Boere JF, Folkerts G, Cassee FR, et al. Microbiome composition of airborne particulate matter from livestock farms and their effect on innate immune receptors and cells. Sci Total Environ. 2019;688:1298-307. https://doi.org/10.1016/ j.scitotenv.2019.06.217

15. Tang Q, Huang K, Liu JZ, Shen D, Dai PY, Li YS, et al. Seasonal variations of microbial assemblage in fine particulate matter from a nursery pig house. Sci Total Environ. 2020;708:134921. https://doi.org/10.1016/j.scitotenv.2019.134921

16. White JK, Nielsen JL, Madsen AM. Microbial species and biodiversity in settling dust within and between pig farms. Environ Res. 2019;171:558-67. https://doi.org/10.1016/j.envres.2019.01.008

17. Liu H, Zhang X, Zhang H, Yao X, Zhou M, Wang J, et al. Effect of air pollution on the total bacteria and pathogenic bacteria in different sizes of particulate matter. Environ Pollut. 2018;233:483-93. https://doi.org/10.1016/j.envpol.2017.10.070

18. Wang X, Tsai T, Deng F, Wei X, Chai J, Knapp J, et al. Longitudinal investigation of the swine gut microbiome from birth to market reveals stage and growth performance associated bacteria. Microbiome. 2019;7:109. https://doi.org/10.1186/s40168-019-0721-7

19. Yu Z, Morrison M. Improved extraction of PCR-quality community DNA from digesta and fecal samples. Biotechniques. 2004;36:808-12. https://doi.org/10.2144/04365ST04 
20. Baek YC, Choi H, Jeong JY, Lee SD, Kim MJ, Lee S, et al. The impact of short-term acute heat stress on the rumen microbiome of Hanwoo steers. J Anim Sci Technol. 2020;62:208-17. https://doi.org/10.5187/jast.2020.62.2.208

21. Magoč T, Salzberg SL. FLASH: fast length adjustment of short reads to improve genome assemblies. Bioinformatics. 2011;27:2957-63. https://doi.org/10.1093/bioinformatics/btr507

22. Caporaso JG, Kuczynski J, Stombaugh J, Bittinger K, Bushman FD, Costello EK, et al. QIIME allows analysis of high-throughput community sequencing data. Nat Methods. 2010;7:335-6. https://doi.org/10.1038/nmeth.f.303

23. Lee KW, Kim M, Lee CH. Treatment of dextran sulfate sodium-induced colitis with mucosa-associated lymphoid tissue lymphoma translocation 1 inhibitor MI-2 is associated with restoration of gut immune function and the microbiota. Infect Immun. 2018;86:e00091. https:// doi.org/10.1128/IAI.00091-18

24. Reddy KE, Kim HR, Jeong JY, So KM, Lee S, Ji SY, et al. Impact of breed on the fecal microbiome of dogs under the same dietary condition.J Microbiol Biotechnol. 2019;29:1947-56. https://doi.org/10.4014/jmb.1906.06048

25. Borlée F, Yzermans CJ, Aalders B, Rooijackers J, Krop E, Maassen CBM, et al. Air pollution from livestock farms is associated with airway obstruction in neighboring residents. Am J Respir Crit Care Med. 2017;196:1152-61. https://doi.org/10.1164/rccm.201701-0021OC

26. Kraemer JG, Aebi S, Oppliger A, Hilty M. The indoor-air microbiota of pig farms drives the composition of the pig farmers' nasal microbiota in a season-dependent and farm-specific manner. Appl Environ Microbiol. 2019;85:e03038. https://doi.org/10.1128/AEM.03038-18

27. Varel VH, Yen JT. Microbial perspective on fiber utilization by swine. J Anim Sci. 1997;75:2715-22. https://doi.org/10.2527/1997.75102715x

28. Zhu J. A review of microbiology in swine manure odor control. Agr Ecosyst Environ. 2000;78:93-106. https://doi.org/10.1016/S0167-8809(99)00116-4

29. Wang $\mathrm{H}, \mathrm{Xu} \mathrm{R}$, Zhang $\mathrm{H}$, Su Y, Zhu W. Swine gut microbiota and its interaction with host nutrient metabolism. Anim Nutr. 2020;6:410-20. https://doi.org/10.1016/j.aninu.2020.10.002

30. Noh HS, Ingale SL, Lee SH, Kim KH, Kwon IK, Kim YH, et al. Effects of citrus pulp, fish by-product and Bacillus subtilis fermentation biomass on growth performance, nutrient digestibility, and fecal microflora of weanling pigs. J Anim Sci Technol. 2014;56:10. https://doi. org/10.1186/2055-0391-56-10

31. Valeriano VDV, Balolong MP, Kang DK. Probiotic roles of Lactobacillus sp. in swine: insights from gut microbiota.J Appl Microbiol. 2017;122:554-67. https://doi.org/10.1111/jam.13364

32. Reddy KE, Jeong JY, Song J, Lee Y, Lee HJ, Kim DW, et al. Colon microbiome of pigs fed diet contaminated with commercial purified deoxynivalenol and zearalenone. Toxins. 2018;10:347. https://doi.org/10.3390/toxins10090347

33. Huang JQ, Zhang WJ, Hu ZY, Liu ZG, Du TH, Dai YM, et al. Isolation, characterization and selection of potential probiotic lactic acid bacteria from feces of wild boar, native pig and commercial pig. Livest Sci. 2020;237:104036. https://doi.org/10.1016/j.livsci.2020.104036

34. Yang H, Xiao Y, Wang J, Xiang Y, Gong Y, Wen X, et al. Core gut microbiota in Jinhua pigs and its correlation with strain, farm and weaning age.J Microbiol. 2018;56:346-55. https://doi. org/10.1007/s12275-018-7486-8

35. Kiu R, Hall LJ. An update on the human and animal enteric pathogen Clostridium perfringens. Emerg Microbes Infect. 2018;7:141. https://doi.org/10.1038/s41426-018-0144-8

36. Kim M, Park T, Yun JI, Lim HW, Han NR, Lee ST. Investigation of age-related changes in the skin microbiota of Korean women. Microorganisms. 2020;8:1581. https://doi.org/10.3390/ microorganisms 8101581 
37. Foster AP. Staphylococcal skin disease in livestock. Vet Dermatol. 2012;23:342-51. https://doi. org/10.1111/j.1365-3164.2012.01093.x

38. Vestergaard DV, Holst GJ, Basinas I, Elholm G, Schlünssen V, Linneberg A, et al. Pig farmers' homes harbor more diverse airborne bacterial communities than pig stables or suburban homes. Front Microbiol. 2018;9:870. https://doi.org/10.3389/fmicb.2018.00870

39. Masclaux FG, Sakwinska O, Charrière N, Semaani E, Oppliger A. Concentration of airborne Staphylococcus aureus (MRSA and MSSA), total bacteria, and endotoxins in pig farms. Ann Occup Hyg. 2013;57:550-7. https://doi.org/10.1093/annhyg/mes098

40. Goyette-Desjardins G, Auger JP, Xu J, Segura M, Gottschalk M. Streptococcus suis, an important pig pathogen and emerging zoonotic agent-an update on the worldwide distribution based on serotyping and sequence typing. Emerg Microbes Infect. 2014;3:1-20. https://doi. org/10.1038/emi.2014.45

41. Yi J, Zheng R, Li F, Chao Z, Deng CY, Wu J. Temporal and spatial distribution of Bacillus and Clostridium histolyticum in swine manure composting by fluorescent in situ hybridization (FISH). Appl Microbiol Biotechnol. 2012;93:2625-32. https://doi.org/10.1007/s00253-011-3558-y

42. Kim M, Yun JI, Won SG, Park KH. Changes of microbial diversity during swine manure treatment process. Pol J Microbiol. 2018;67:109-12. https://doi.org/10.5604/01.3001.0011. 6150

43. Pahalagedara ASNW, Flint S, Palmer J, Subbaraj A, Brightwell G, Gupta TB. Antimicrobial activity of soil clostridium enriched conditioned media against Bacillus mycoides, Bacillus cereus, and Pseudomonas aeruginosa. Front Microbiol. 2020;11:608998. https://doi.org/10.3389/ fmicb.2020.608998

44. Veith B, Herzberg C, Steckel S, Feesche J, Maurer KH, Ehrenreich P, et al. The complete genome sequence of Bacillus licheniformis DSM13, an organism with great industrial potential.J Mol Microbiol Biotechnol. 2004;7:204-11. https://doi.org/10.1159/000079829

45. Stenfors Arnesen LP, Fagerlund A, Granum PE. From soil to gut: Bacillus cereus and its food poisoning toxins. FEMS Microbiol Rev. 2008;32:579-606. https://doi.org/10.1111/j.15746976.2008.00112.x

46. Vela AI, García N, Latre MV, Casamayor A, Sánchez-Porro C, Briones V, et al. Aerococcus suis sp. nov., isolated from clinical specimens from swine. Int J Syst Evol Microbiol. 2007;57:1291-4. https://doi.org/10.1099/ijs.0.64537-0

47. Moreno LZ, Matajira CEC, Gomes VTM, Silva APS, Mesquita RE, Christ APG, et al. Molecular and antibiotic susceptibility characterization of Aerococcus viridans isolated from porcine urinary infection. Vet Microbiol. 2016;184:7-10. https://doi.org/10.1016/j.vetmic.2016.01.002

48. Kumari P, Woo C, Yamamoto N, Choi HL. Variations in abundance, diversity and community composition of airborne fungi in swine houses across seasons. Sci Rep. 2016;6:37929. https:// doi.org/10.1038/srep37929

49. Ding L, Yokota A. Curvibacter fontana sp. nov., a microaerobic bacteria isolated from well water.J Gen Appl Microbiol. 2010;56:267-71. https://doi.org/10.2323/jgam.56.267

50. Gomila M, Bowien B, Falsen E, Moore ERB, Lalucat J. Description of Pelomonas aquatica sp. nov. and Pelomonas puraquae sp. nov., isolated from industrial and haemodialysis water. Int J Syst Evol Microbiol. 2007;57:2629-35. https://doi.org/10.1099/ijs.0.65149-0

51. Shah V, Subramaniam S. Bradyrhizobium japonicum USDA110: a representative model organism for studying the impact of pollutants on soil microbiota. Sci Total Environ. 2018;624:963-7. https://doi.org/10.1016/j.scitotenv.2017.12.185

52. Wu S, Zhong L, Liao S, Li T, Zhou Z, Wang G. Sediminibacterium soli sp. nov., isolated from soil. Arch Microbiol. 2020:203:967-73. https://doi.org/10.1007/s00203-020-02089-2 